\title{
Long-term recurrence in nonfunctional pituitary adenomas after surgery
}

Rodriguez Caballero M.G., Valdés Gallego N., Sánchez Ragnarsson C., Pertierra de la Uz J., Cacho L., Rabal Artal A., Ares J., Delgado E., Menéndez Torre E. ${ }^{1}$

1. Servicio de Endocrinología y Nutrición del Hospital Universitario Central de Asturias, Spain

\section{OBJECTIVES}

Nonfunctioning pituitary adenomas (NFPA)
can experiment recurrence and/or
progression (R/P) several years after
surgery in about 15-50\% of patients. There
is few evidence about risk factors that
could predict R/P. The aim of this study is
to identify them and describe our
experience through a long term of follow
up in pituitary macroadenomas.

\section{METHODS}

Retrospective cohort analysis of 64 patients who underwent surgery between 19902013. The main outcome was to evaluate prevalence of $R / P$ during the follow-up, based on imaging criteria and identify some risk factors for $R / P$.

\section{RESULTS}

Over a median follow up of 10,12 years, there was $46 \%$ of R/P after surgery at a median time of 4,6 years, the cumulative risk of being free of R/P was $62 \%$ by 5 years and decrease to $45 \%$ by 15 years after surgery. Multivariate cox proportional hazard regression analysis identified the following risk factors as associated with increased risk of recurrence: radiotherapy after surgery (hazard ratio 2.90, 95\% confidence interval $1.15-7.46, \mathrm{P}=0.023$ ) and the tumor size at diagnosis (hazard ratio 1.05 confidence interval $1.009-1.10, \mathrm{P}=0,019)$.
Kaplan- Meier estimates of Recurrence and /or Progression (R/P)

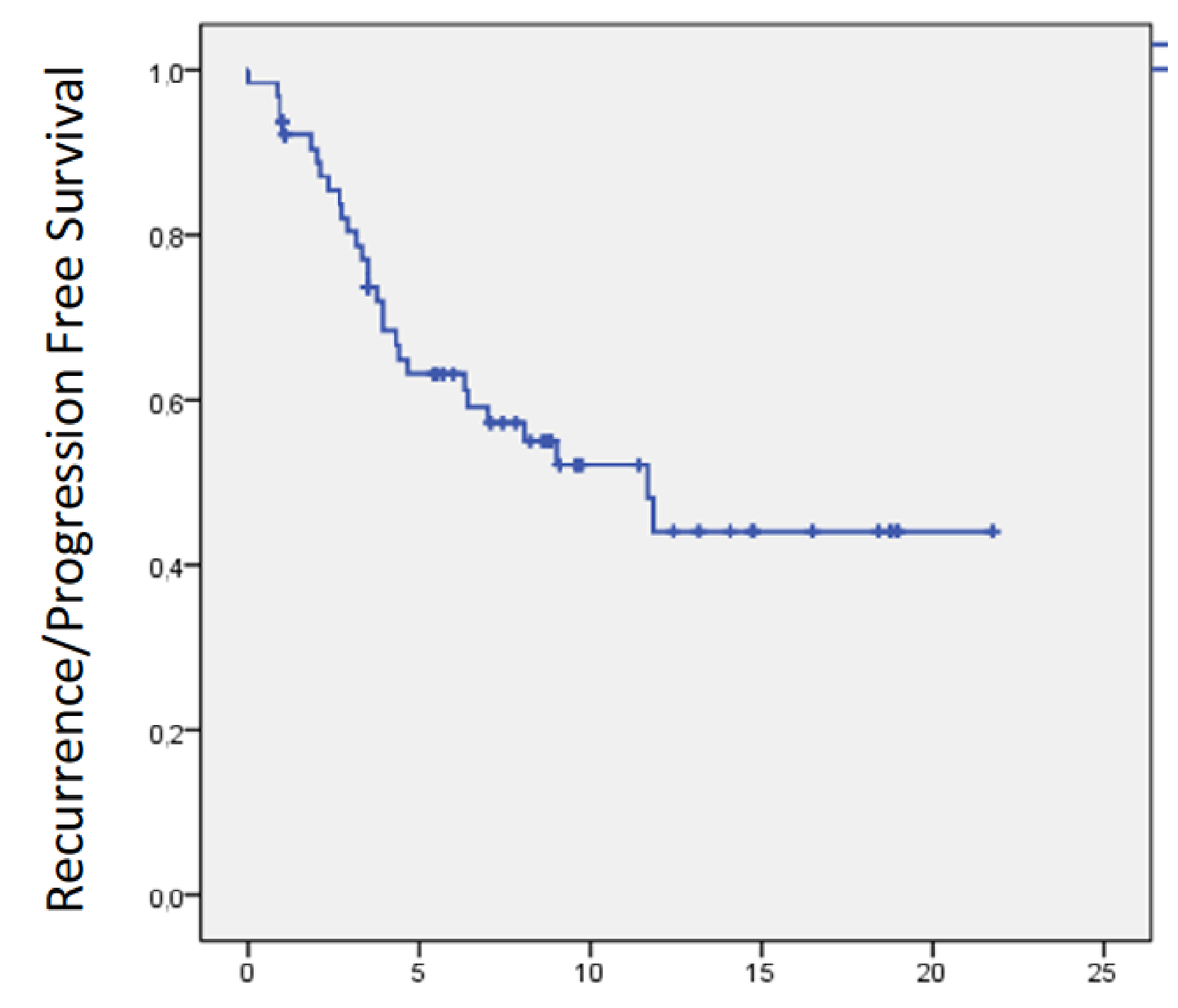

Follow-up (years)

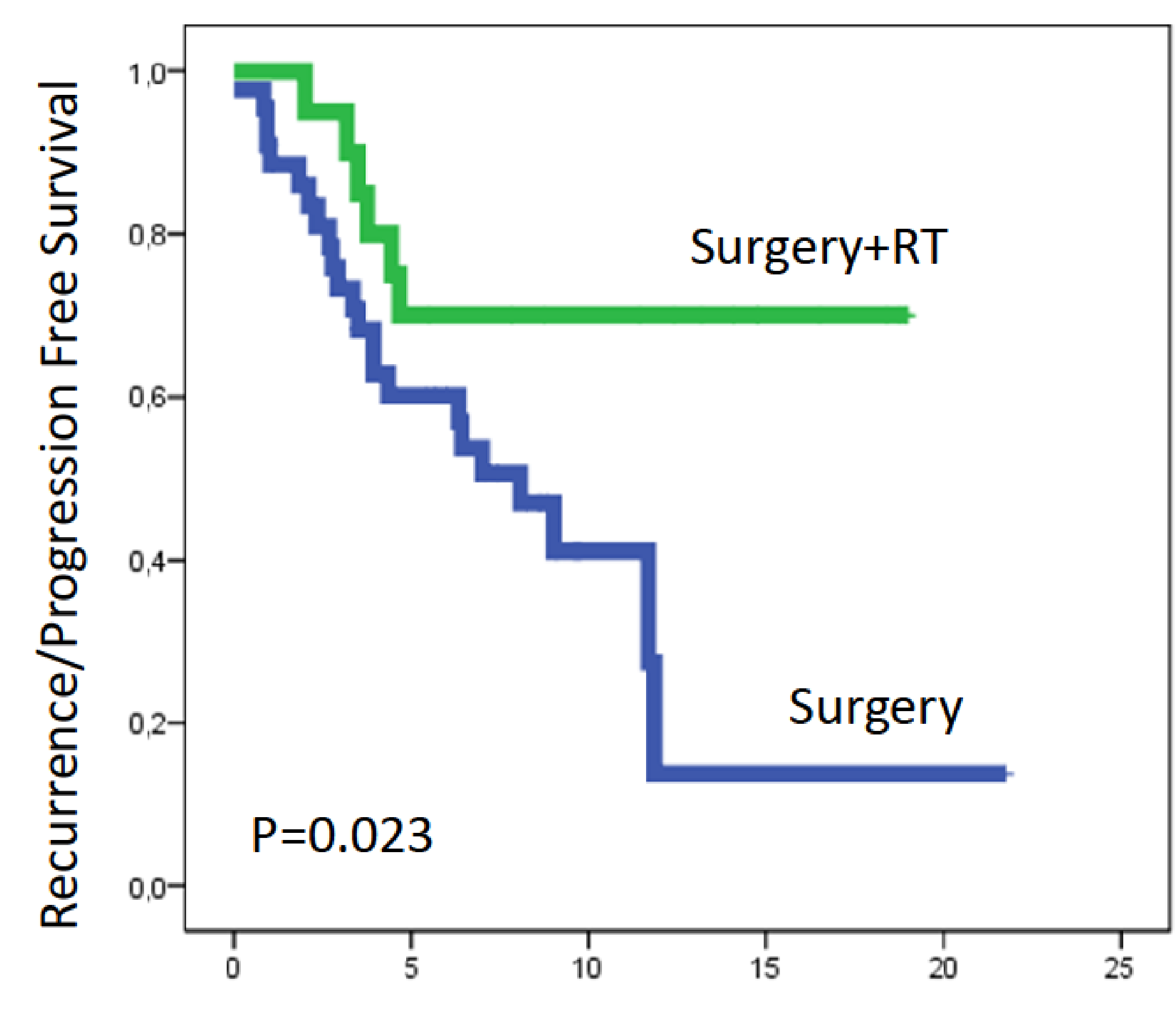

Follow-up (years)

$\begin{gathered}\text { Logistic Regression } \\ \text { Analyses }\end{gathered}$
univariate
Age (years)
Male sex
Hypopytuitarysm
Pituitary apoplexy
Pathologic campimetry
Invasive tumor
Quisma compression
Rests after surgery
multivariate
Tumor size (mm)
Postoperative RT

\begin{tabular}{|c|c|}
\hline HR (95\% IC) & P Value \\
\hline $\begin{array}{c}0.99 \\
(0.97-1.02)\end{array}$ & 0.66 \\
\hline $\begin{array}{c}1.2 \\
(0.56-2.56)\end{array}$ & 0.63 \\
\hline $\begin{array}{c}2.8 \\
(0.38-20.86)\end{array}$ & 0.30 \\
\hline $\begin{array}{c}1.8 \\
(0.68-4.77)\end{array}$ & 0.23 \\
\hline $\begin{array}{c}1.41 \\
(0.61-3.25)\end{array}$ & 0.37 \\
\hline $\begin{array}{c}2.58 \\
(0.24-3.08)\end{array}$ & 0.064 \\
\hline $\begin{array}{c}1.71 \\
(0.78-3.71)\end{array}$ & 0.17 \\
\hline $\begin{array}{c}1,64 \\
(0,36-7.35)\end{array}$ & 0.51 \\
\hline $\begin{array}{c}1.05 \\
(1.009-1.10)\end{array}$ & 0.019 \\
\hline $\begin{array}{c}2.90 \\
(1.15-7.46)\end{array}$ & 0.023 \\
\hline
\end{tabular}

Table: Predictors of R/P

\section{CONCLUSIONS}

Patients with NFPA need long-term follow up because they have a high risk of R/P over time. Radiotherapy after surgery decreases the risk of recurrence or progression specially after 5 years. The tumor size at diagnosis is an independently risk of R/P. 